\title{
EFFECTS OF SALT STRESS ON EXPRESSION LEVEL OF StDREB2 TRANSCRIPTION FACTOR AND MICROTUBERIZATION OF DIFFERENT POTATO GENOTYPES
}

\author{
N. K. Şahin ${ }^{1}$, B. Benlioğlu ${ }^{1}$, H. A. A. Ahmed ${ }^{2}$ and S. Uranbey ${ }^{1 *}$ \\ ${ }^{1}$ Ankara University, Agriculture Faculty, Department of Field Crops, 06100 Ankara/Turkey \\ ${ }^{2}$ Uşak University, Faculty of Agriculture and Natural Sciences Department of Field Crops, 64200 Uşak/ Turkey \\ "Corresponding author's e-mail: uranbey@ankara.edu.tr
}

\begin{abstract}
Salt stress considerably limits plant development and growth and it has detrimental effects on crop production. Potato is also one of the moderately sensitive crops to salinity and it is very important to improve new potato varieties conferring salt tolerance. In vitro micro tubers are valuable materials for evaluation and in vitro selection of potato germplasm. The main aim of this study was to reveal the effects of different salt concentrations $(100,200$ and $300 \mathrm{mM})$ on microtuberization of four potato cultivars i.e., Slaney, Granola, Rasin Busset and Agria. In addition to detect expression levels of dehydration-responsive element binding 2 (StDREB2) transcription factor involving in the transcriptional regulation of gene expression to various salt stresses in potato. On average, in all the potato cultivars the production of microtubers was drastically affected and decreased with increased salt intensity. The highest explant ratio forming micro tuber (66.6 \%) and the highest number of micro-tubers (0.88) micro tubers / explant) were observed in cultivar Slaney. However, Granola could not produce any microtuber under salt stress conditions. The RT-qPCR regarding StDREB2 relative gene expression levels showed noticeable differences among potato genotypes for various $\mathrm{NaCl}$ concentrations. StDREB2 gene relative gene expression level was also up regulated at $100 \mathrm{mM}$ and higher salt concentrations for almost all the cultivars except cv. Granola.
\end{abstract}

Key words: Potato, salt, microtuberization, transcription factor, DREB, StDREB2.

https://doi.org/10.36899/JAPS.2020.5.0142

Published online June 25, 2020

\section{INTRODUCTION}

Potato (Solanum tuberosum L.) is one of the most important crops grown throughout the world despite the popularity of low carbohydrate foods. Potato crop can meet the increasing hunger problem and balanced diet and the crop is becoming increasingly popular worldwide. Abiotic and biotic stress factors have important disruptive impacts on crop production. Potato can also be severely and negatively influenced by different biotic and stress abiotic factors during the growing period. Although improvements of new varieties is slow due to the genetic complexity of potato ( $\mathrm{Su}$ et al. 2019), there is an urgent need for new resistant potato varieties against stress factors. Salt is an extremely toxic substance for plants (Zhu, 2007) and salinity in arable lands has been increasing in the world. Therefore, salinity is one of the most important abiotic constraints on field and horticultural crops production (Evers et al., 2007). The severity of salt stress varies according to plant species, salt type, duration of salt stress, plant genotype and stage of growth/development. Plants give a complex respond to salt stress at physiological, metabolic and molecular levels (Chinnusamy and Zhu, 2002). Under salt stress conditions, some important genes encoding proteins belonging to osmolite synthesis, ion channels, signal factors and salt response enzymes are activated depending on the genetic characteristics of the plant species (Kreps et al., 2002; Tuteja, 2007; Zhu, 2007; Çulha and Çakırlar, 2011). Plants have complicated mechanisms to regulate the expression of defence-related genes against biotic and abiotic stress factors. Transcription factors (TF) also have an important role in a regulation network of plant defence responses (Van Verk et al., 2009). They are functional in regulating downstream gene expression via specific binding to target sequences (Yamaguchi-Shinozaki and Shinozaki, 2006). There are many TFs regulating the expressions of stress genes in enhancing stress tolerance (Liu et al., 1999; Behnam, et al., 2006; Behnam et al., 2007; Bouaziz et al., 2012; Mizoi et al., 2012; Reis et al., 2014; Bouaziz et al., 2015; Charfeddine et al., 2017). The dehydration responsive element binding proteins (DREB) are also one of the members of a larger family of transcription factors and these TFs are involved in the transcriptional regulation of gene expression in plant response to environmental stresses as cold, drought, improved oxidative, freezing and salinity and they have an important function in regulating stresses tolerance pathways (Stockinger et al., 1997; Thomashow, 2001; Yamaguchi-Shinozaki and Shinozaki, 2006; Gutha and Reddy, 2008; Xu et al., 2011; Bouaziz et al., 2012; Elesawi and Alayafi, 2019). The DREB factors encodes a functional protein against different abiotic stress factors 
and induce the expression of some target genes controlling metabolism (Lata and Prasad, 2011; Hussain et al., 2011; Bouzaziz et al., 2012). DREB TF belonging to AP2/ERF family contain DREB1 and DREB 2 (Yamaguchi-Shinozaki et al., 1994; Stockinger et al., 1997; Mizoi et al., 2012; El-esavi and Alayafi, 2019) have been recently identified in different plants such as Arabidopsis (Stockinger et al., 1997), potato (Bouaziz et al., 2012), rice (Dubouzet et al., 2003), hot pepper (Hong and Kim, 2005), soybean (Chen et al., 2007), Caragana korshinskii (Wang et al., 2011). Salt stress induced StDREB2 transcript accumulation in potato and overexpression of StDREB2 in transgenic potato plants increased tolerance to salt and cadmium (Bouaziz et al., 2012; Charfeddine et al., 2017). The saline lands have been threatening the production of potato due to the increase of the irrigated areas in the world. Potato with its rich nutritional composition is also one of the moderately sensitive crops to salinity under in vitro and in vivo conditions (Maas, 1984; Saif-Ur-Rasheed et al., 1998, Katerji et al., 2003). Many different metabolic and physiological changes also occur under salt stress and gene and transcription factors are involved in these processes in potato (Batelli et al., 2012; Shimazaki et al., 2016; Uranbey et al., 2017) and tolerance to salt varies significantly depending on varieties of potato.

In vitro techniques and micropropagation are very fast, reliable an actual methods for screening of potato varieties under salinity stress (Byun et al., 2007, Ahmed et al., 2016). In vitro micro tubers in potato are valuable materials for disease-free, long-term preservation and transport of genetic material, evaluation and suitability of germplasm for in vitro selection (Uranbey et al., 2017) and also an important source of explants for genetic transformation studies (Uranbey et al., 2005; Ahmed et al. 2018). Microtuberization of potato is highly related to external factors such as temperature, light source and intensity, photoperiod, sugar type and concentrations, solidifiers, growth regulator types, basal media (Coleman et al., 2001; Zhang et al., 2006; Aryakia and Hamidoghli, 2010). There are limited literatures about salinity effects on in vitro microtuberization of potato (Amerian and EsnaAshari, 2011; Ahmed et al., 2016, Koçak et al., 2016). The goal of this experiment was also to reveal the effects of various salt concentrations on microtuberization of different potato varieties and to detect the expressional levels of the StDREB2 transcription factor response by qRT-PCR.

\section{MATERIALS AND METHODS}

Plant material: Four potato cultivars (Slaney, Basin Russet, Agria and Granola intensively cultivated in Turkey) were used in the study.
Tuber sterilization and sprouting: The fresh harvested tubers of the potato cultivars were washed with tap water and surface sterilized using $5.0 \% \mathrm{NaOCl}$ for $20 \mathrm{~min}$. The tubers were rinsed with sterile double distilled water. The tubers were stored and sprouted at $24{ }^{\circ} \mathrm{C}$ under dark conditions for 4-6 weeks. Then, the tubers were kept at $4^{\circ} \mathrm{C}$ in a solution containing $100 \mathrm{ppm} \mathrm{GA}_{3}$ for 60 minutes for breaking the dormancy. The developed fresh sprouts (approximately $0.5 \mathrm{~cm}$ length) after 4-6 weeks were excised and sterilized with $1.25 \% \mathrm{NaOCl}$ for $20 \mathrm{~min}$ and rinsed four times with sterilized distilled water. Then, the apical buds were transferred to MS medium (Murashige and Skoog, 1962) containing $30 \mathrm{~g} \mathrm{~L}^{-1}$ sucrose with $0.3 \%$ gelrite and incubated under $16 / 8 \mathrm{~h}$ photoperiod $149 \mu \mathrm{mol}$ $\mathrm{m}^{-2} \mathrm{~s}^{-1}$ photosynthetic photon flux density at $24^{\circ} \mathrm{C}$. Shoot cultures were established from sprouts and propagated by single-node stem explants. The explants were transferred to fresh media at three weeks interval.

Microtuber induction, salt stress and $\mathbf{A B A}$ treatments: Single node stem segments $(0.5-\mathrm{cm}$ length) with single-leaf in 4-5 weeks-old plantlets were excised and cultured on only MS medium or MS medium containing 0, 100, 200, $300 \mathrm{mM} \mathrm{NaCl}, 2.5 \mathrm{mg} / \mathrm{L}$ Kinetin, $60 \mathrm{~g} / \mathrm{L}$ sucrose and $7 \mathrm{~g} / \mathrm{L}$ agar for microtuberization studies. Moreover, single node with single leaf were also cultured on MS medium containing 0, 100, 200, $300 \mathrm{mM}$ NaCl., $1 \mathrm{mg} / \mathrm{L}$ 6-Benzylaminopurine (BAP) $30 \mathrm{~g} / \mathrm{L}$ sucrose with $7 \mathrm{~g} / \mathrm{L}$ agar for $\mathrm{qRT}$-PCR studies under white fluorescence at $24^{\circ} \mathrm{C}$. Roots of plantlets with 8 weeksold were exposed to $1000 \mathrm{ppm}$ Abscisic acid (ABA) hormone to induce TF. All cultures were maintained under dark conditions at $22-24^{\circ} \mathrm{C}$.

RNA isolation: Leaves of plantlets grown under salt stress conditions were cut and frozen in liquid nitrogen $\&$ stored at $-85{ }^{\circ} \mathrm{C}$ for RNA extraction. Total RNA was isolated from leaf tissue using TRIzol kit (Invitrogen) and treated with DNase (\#EN0521 Thermo Scientific) to eliminate genomic DNA contamination.

qRT-PCR analysis: Total RNA was used to make firststrand cDNA with the ReversAid First Strand cDNA Synthesis Kit (\#K1622 Thermo Scientific) using oligo-dT primers. PCR was performed using cDNA created with Oligo (dT) primers (R) 5' GTCGATTCTGGAAAGTCGACC-3', (F) 3'AATGTCAATGGTGATACCACGC-5' for amplification of EFla (Elongation factor). EFIa was used as housekeeping control and gene-specific primers were designed using the specific gene primers designed for StDREB2 as described by Bouzaziz et al., 2012. The PCR reaction $(20 \mu \mathrm{l})$ composed of $1 \mathrm{X}$ SYBR Green master mix, $2 \mu \mathrm{g}$ cDNA, $7 \mu \mathrm{M}$ Forward Primer, $0.7 \mu \mathrm{M}$ Reverse Primer, $3.5 \mu \mathrm{H}_{2} \mathrm{O}$. The PCR conditions were $2 \mathrm{~min}$ at $96{ }^{\circ} \mathrm{C}$ followed by 40 cycles at $96{ }^{\circ} \mathrm{C}$ for $20 \mathrm{~s}, 60{ }^{\circ} \mathrm{C}$ for $20 \mathrm{~s}$, $72{ }^{\circ} \mathrm{C}$ for $20 \mathrm{~s}$. qRT-PCR reactions were performed in 
triplicates (three biological) using SYBR Green PCR kit (Qiagen) described by the company's protocol. The melting curve was continuous monitoring of fluorescence between 60 and $95{ }^{\circ} \mathrm{C}$ with $0.5^{\circ} \mathrm{C}$ cumulation after every 30 s. ${ }^{\Delta} \mathrm{CT}$ data were processed in Roche Light Cycler software. As a result of PCR, Ct (Cycle Threshold) values were obtained for each sample. Expression levels of StDREB2 were calculated and estimated using the $2^{\text {(- }}$ Delta DeltaCt) method.

Statistical methods: The experiments were conducted as a Completely Randomized Design (CRD) (two-way ANOVA) with two factors (fixed affected) in three replications. We used Levene' s test to check homogenity of variances before ANOVA tests. Differences between the means were compared by Duncan's multiple range tests using MSTAT-C computer programme (Michigan State University) as stated by Düzgüneş et al., (1983). Data given in percentages were subjected to arcsine $(\sqrt{ } \mathrm{X})$ transformation before statistical analysis.

\section{RESULTS AND DISCUSSION}

Microtuberization capacity of potato genotypes under salt stress: Microtuberization started from the bottom of the axillary buds after 3 weeks culture initation from the control explants and secondary microtuber formations occurred on the developed stem after about 2 weeks. Initiation of small and weak microtubers appeared within 5-6 weeks at higher salt concentrations (100-200 mM) for Slaney, Basin Russet and Agria cultivars. The number of micro tubers per explant and the explant ratio forming micro tuber were scored after 10-12 weeks culture initation. There were statistically significant differences in terms of microtuberization capacity among potato cultivars $(\mathrm{P}<0.01)$ and there were interactions between cultivars and salt concentrations. Each salt concentrations were compared for each cultivar (Table 1). The cultivars showed various microtuberization responses at the different salt concentrations.

MS medium containing KIN resulted in robust micro tuber proliferation in control plantlets of the all cultivars tested. Microtuberization of all potato cultivars tested was delayed up to 3-4 weeks days at higher salt concentrations (at 200-300 mM NaCl). Slaney cv. had the maximum explant ratio forming micro tuber and the highest number of micro tuber per explant on MS medium without $\mathrm{NaCl}$. The highest explant ratio forming micro tuber $(66.6 \%)$ and the highest number of micro tubers ( 0.88 micro tubers / explant) were also determined in Slaney cv under salt stress conditions at $100 \mathrm{mM}$ $\mathrm{NaCl}$. Microtuberization decreased drastically at 100 $\mathrm{mM}$ and higher concentrations of $\mathrm{NaCl}$ in Slaney. However, it was observed that the cultivar was able to form microtubers with weak and small diameter (diameter less than $0.2 \mathrm{~mm}$ ) even at $200 \mathrm{mM} \mathrm{NaCl}$ concentration. Microtuberization was completely inhibited at high concentrations of $\mathrm{NaCl}$ (200-300 mM) in other cultivars and we observed that the stolon growth of the all cultivars was not negatively affected by salt concentrations. Basin Russet and Agria showed also microtuberization performance at $100 \mathrm{mM} \mathrm{NaCl} .100$ $\mathrm{mM}$ and higher concentrations of $\mathrm{NaCl}$ inhibited stolon growth and microtuberization of both cultivars. Microtuber production drastically decreased as increasing salt intensity for all genotypes as reported by Koçak et al. (2016). Three salt concentrations used in this experiment revealed that salinity has significant negative effects on potato microtuberization. Slaney exhibited best microtuberization capacity when compared to the other genotypes. Salinity causes reduction of the water and $\mathrm{CO}_{2}$ assimilation, osmotic imbalance, nutritional defects in plants (Chinnusamy and Zhu, 2003). Osmatic pressure reduction probably may resulted in $\mathrm{CO}_{2}$ assimilation in the leaves and in the cells of stolon and storage tissues. Osmatic stress also reduces the yield power of water and salinity has suppressive effects on growth, development and tuberization of potato under in vitro and ex vitro conditions. High salt concentrations prevent intake of nutrients and water and most likely negatively affects microtuberization as indicated in the study.

Table 1. The influence of $\mathrm{NaCl}$ doses on microtuberization of potato cultivars.

\begin{tabular}{|c|c|c|}
\hline Slaney & $\begin{array}{c}\text { The number of tubers } \\
\text { per explant }\end{array}$ & $\begin{array}{c}\text { The explant ratio } \\
\text { forming micro tuber }\end{array}$ \\
\hline 0 & $3.13^{\mathrm{a}}$ & $100.00 \mathrm{a}$ \\
\hline 100 & $0.88^{\mathrm{b}}$ & $66.6 \mathrm{~b}$ \\
\hline 200 & $0.77^{\mathrm{b}}$ & $13.3 \mathrm{c}$ \\
\hline 300 & $0.00^{\mathrm{c}}$ & $0.0 \mathrm{c}$ \\
\hline $\begin{array}{l}\text { Basin } \\
\text { Russet }\end{array}$ & $\begin{array}{c}\text { The number of tubers } \\
\text { per explant }\end{array}$ & $\begin{array}{c}\text { The explant ratio } \\
\text { forming micro tuber }\end{array}$ \\
\hline 0 & $2.88^{\mathrm{a}}$ & $93.3 \mathrm{a}$ \\
\hline 100 & $1.33^{\mathrm{b}}$ & $27.6 \mathrm{~b}$ \\
\hline 200 & $0.00^{\mathrm{c}}$ & $0.00 \mathrm{c}$ \\
\hline 300 & $0.00^{\mathrm{c}}$ & $0.00 \mathrm{c}$ \\
\hline Agria & $\begin{array}{c}\text { The number of tubers } \\
\text { per explant }\end{array}$ & $\begin{array}{c}\text { The explant ratio } \\
\text { forming micro tuber }\end{array}$ \\
\hline 0 & $2.66 \mathrm{a}$ & $100.0 \mathrm{a}$ \\
\hline 100 & $0.66 \mathrm{~b}$ & $33.3 \mathrm{~b}$ \\
\hline 200 & $0.00 \mathrm{c}$ & $0.00 \mathrm{c}$ \\
\hline 300 & $0.00 \mathrm{c}$ & $0.00 \mathrm{c}$ \\
\hline Granola & $\begin{array}{c}\text { The number of tubers } \\
\text { per explant }\end{array}$ & $\begin{array}{c}\text { The explant ratio } \\
\text { forming micro tuber }\end{array}$ \\
\hline 0 & $1.46 \mathrm{a}$ & $83.3 \mathrm{a}$ \\
\hline 100 & $0.00 \mathrm{~b}$ & $0.00 \mathrm{~b}$ \\
\hline 200 & $0.00 \mathrm{~b}$ & $0.00 \mathrm{~b}$ \\
\hline 300 & $0.00 \mathrm{~b}$ & $0.00 \mathrm{~b}$ \\
\hline
\end{tabular}


StDREB2 expression in potato genotypes under salt stress: Although no morphological differences and relative deterioration were observed at all salt concentrations for all cultivars tested. Moreover, shoot length, number of node, number of leaflet, leaflet length, leaflet width, number of root, root length, fresh root weight, dry root weight, fresh plantlet weight, dry plantlet weight were negatively influenced as previously reported by Ahmed et al., (2016) (Fig. 1). All cultivars were morphologically affected by salinity doses (Fig.1). It was observed that Slaney were less affected by salt concentrations (Fig.1a), however, Granola was negatively affected by salt and developed weakly (Fig 1.b). Salttolerant Slaney cv exhibited significant phenotypic differences from the control plants.

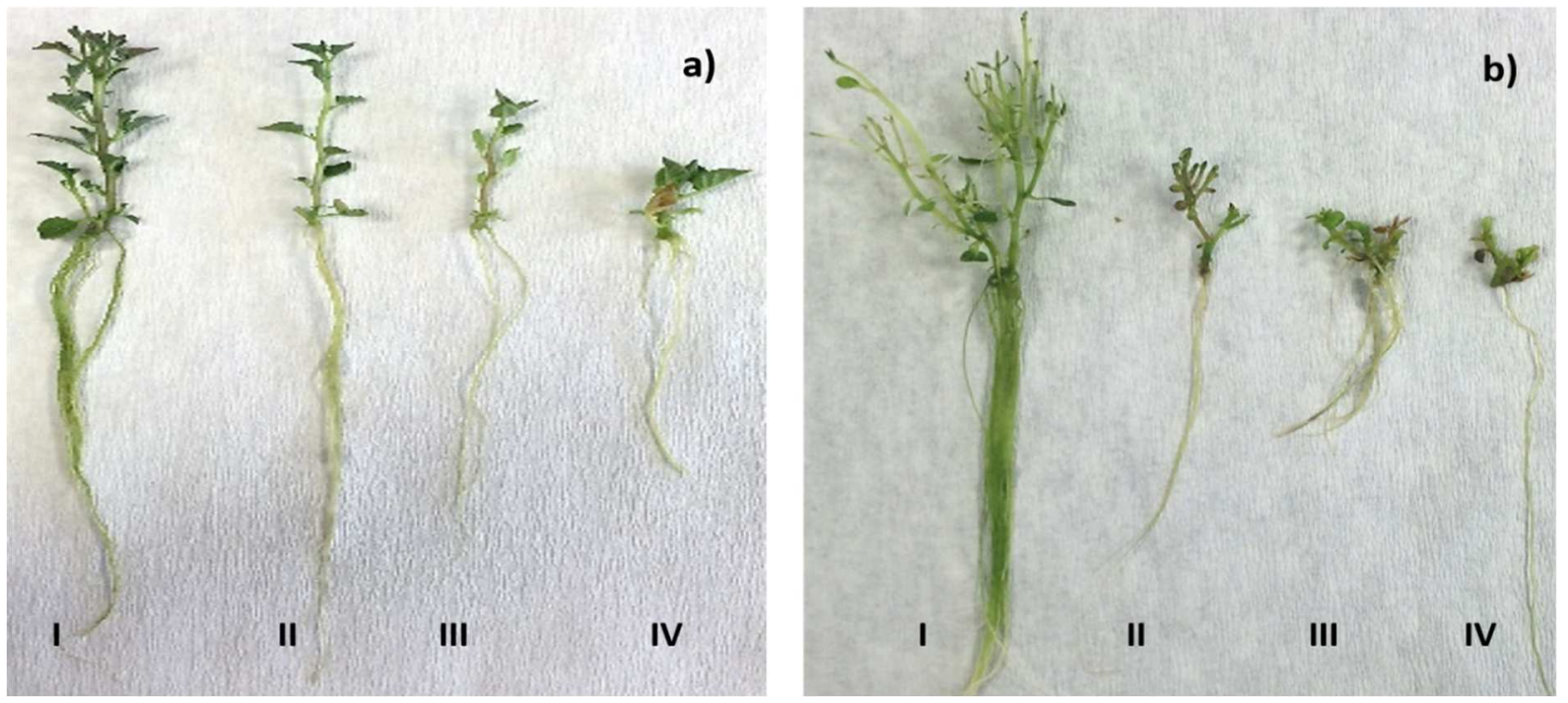

Figure 1. Plantlet growth and development on MS medium containing different concentrations of $\mathrm{NaCl}(0,100$, $200,300 \mathrm{mM} \mathrm{NaCl}$ ) a) Slaney cv b) Granola cv (I) Control, (II) at $100 \mathrm{mM} \mathrm{NaCl}$. (III) at $200 \mathrm{mM} \mathrm{NaCl}$ (IV) at $300 \mathrm{mM} \mathrm{NaCl}$.

Level of StDREB2 expression was affected by salt concentrations in all genotypes tested. Figure 2. represents StDREB2 relative expression in all cultivars at the different salt doses. Real-Time PCR data for each cultivar were normalized according to their control. StDREB2 expression statistically and significantly increased in the Slaney and Agria cultivars at $100 \mathrm{mM}$ $\mathrm{NaCl}$ application compared to the control plants (Fig. 2 . a-b). StDREB2 expression decreased compared to the $100 \mathrm{mM} \mathrm{NaCl}$ and then increased again at $300 \mathrm{mM} \mathrm{NaCl}$ concentrations in Slaney. It was also observed that StDREB2 expression increased about 4-fold at $300 \mathrm{mM}$ $\mathrm{NaCl}$ treatments in Slaney compared to the control plantlets (Fig. 2a). The maximum StDREB2 expression was also observed for Agria and Basin Russet cultivars at $100 \mathrm{mM} \mathrm{NaCl}$. Whereas, StDREB2 expression increased at a low rate at $200 \mathrm{mM}$ and $300 \mathrm{mM} \mathrm{NaCl}$ concentrations for both cultivars. StDREB2 expression levels in Agria significantly and markedly decreased at 200 and $300 \mathrm{mM} \mathrm{NaCl}$ when compared to $100 \mathrm{mM} \mathrm{NaCl}$. Almost identical trend was observed with regards to Basin Russet (Fig. 3c). There was also no statistically significant expression level compared to the control for Basin Russet. Contrarily, totally different pattern was observed, where StDREB2 expression decreased in
Granola under salt treatment compared to control plantlets (Fig. 3d) at 200 and $300 \mathrm{mM} \mathrm{NaCl}$. However, low positive expression of StDREB2 was observed at 100 $\mathrm{mM} \mathrm{NaCl}$. StDREB2 relative expression did not markedly change and the results indicated that there was no significant difference between all salt concentrations and control for Granola.

The results indicated that levels of StDREB2 relative expression were remarkably influenced in all cultivars treated with salt when compared to the control plants. The RT-qPCR regarding StDREB2 relative expression levels in the all potato cultivars revealed that there were noticeable differences among potato cultivars and between each $\mathrm{NaCl}$ concentration. Level of StDREB2 expression was significantly up-regulated at $100 \mathrm{mM}$ and higher salt concentrations for all cultivars. These findings are in agreement and parallel with microtuberization studies of the cultivars evaluated in terms of salinity under salt conditions. StDREB2 expression under salt stress conditions was positively correlated with microtuberization capacities of the potato genotypes in the current study. Rensink et al. (2005) reported that potato cDNA microarray allowed identification of genes encoding transcription factors under cold, heat and salt stress conditions. StDREB2 
transcription factors expression are also involved in the regulation of salt stress in potato and other plants (Bouzaziz et al., 2012; Bouzaziz et al., 2015; Charfeddine et al., 2017; El-esavi and Alayafi, 2019). To induce expression of the StDREB2, plantlets were exposed to ABA in the study. Bouzaziz et al., (2012) indicated that the transcription of StDREB2 gene could give a response to $\mathrm{ABA}$ treatment with changeable expression patterns in potato. The role of StDREB2 against salt stress was revealed by analysis of its expression pattern after exposing to $\mathrm{ABA}$ in the study. Overexpression of StDREB1 cDNA in transgenic potato plants exhibited an improved salt and drought stress and StDREB1 was markedly induced by salt.
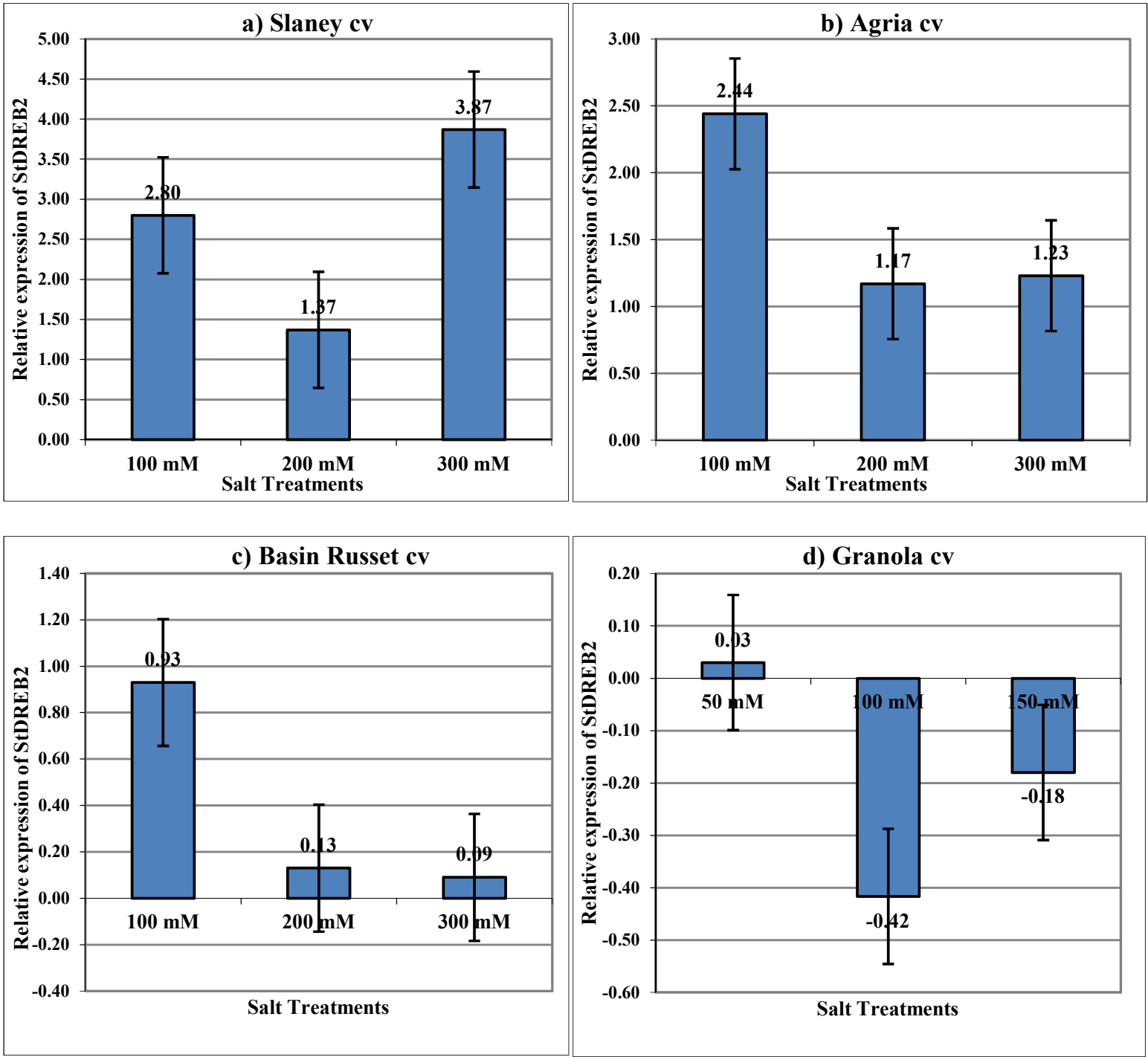

Figure 2. Effects of different salt concentrations on relative expression of StDREB2 a) Slaney cv, b) Agria cv, c) Basin Russet cv and d) Granola cv

In conclusion, the results suggested salt treatments and increasing salt doses dramatically up regulated expression levels of StDREB2. StDREB2 expression could manifold salt stress tolerance and microtuberization capacity of potato. These results also showed that Granola is the most salt sensitive genotype and Slaney and Agria cultiars are salt tolerant genotypes with up-regulation of StDREB2 transcriptions factor playing important role in the regulation of salt stress. Further study of the role of the StDREB2 in responding to salt stresses may also contribute to improve a new varieties, salt tolerant transgenic plants and deeper of understanding of its stress-tolerance signal-regulating mechanisms. 


\section{REFERENCES}

Ahmed, H.A.A., S. Barbete, G. Akdogan, G. Aydin, C. Sancak and S. Ozcan (2018). Efficient regeneration and Agrobacterium tumefaciens mediated genetic transformation of potato. Fresenius Environmental Bulletin. 27(5): 30203027.

Ahmed, H.A.A., N. Koçak, G. Akdoğan, S. Arslan, D. Köm and S. Uranbey (2016). In vitro screening of potato cultivars (Solanum tuberosum L.) under salt stress. The $7^{\text {th }}$ International Scientific Agriculture Symposium. Jahorina Mountain (Bosnia and Herzegovina), 6-9 October.

Amerian, M and M. Esna-Ashari (2011). Effect of $\mathrm{NaCl}$ stress and sucrose on potato microtuberization. Fruit, Vegetable and Cereal Science and Biotechnology. 5 (Special Issue 2):96-98.

Aryakia, E and Y. Hamidoghli (2010). Comparison of kinetin and 6-benzyl amino purine effect on in vitro microtuberization of two cultivars of potato (Solanum tuberosum L.). American-Eurasian J. Agricultural and Environmental Sciences. 8(6):710-714.

Batelli, G., I. Massarelli, M. Van Oosten, R. Nurcato, C. Vannini, G. Raimondi, A. Leone, J.K. Zhu, A. Maggio and S. Grillo (2012). Asg1 is a stressinducible gene which increases stomatal resistance in salt stressed potato. J. Plant Physiology. 169(18):1849-57

Behnam, B., A. Kikuchi, F. Celebi-Toprak, M. Kasuga, $\mathrm{K}$. Yamaguchi-Shinozaki and $\mathrm{K}$. Watanabe (2007). Arabidopsis $r d 29 A:: D R E B 1 A$ enhances freezing tolerance in transgenic potato. Plant Cell Reports. 26(8): 1275-1282.

Behnam, B., K. Kikuchi, F. Celebi-Toprak, S. Yamanaka, M. Kasuga, K. Yamaguchi-Shinozaki and K.N. Watanabe (2006). The Arabidopsis DREB1A gene driven by the stress-inducible rd29A promoter increases salt-stress tolerance in tetrasomic tetraploid potato (Solanum tuberosum L.) in proportion to its copy number. Plant Biotechnology. 23: 169-177.

Bouaziz, D., J. Pirrello, H. Ben Amor, A. Hammami, M. Charfeddine, A. Dhieb, M. Bouzayen and R. Gargouri-Bouzid (2012). Ectopic expression of dehydration responsive element binding proteins (StDREB2) confers higher tolerance to salt stress in potato. Plant Physiology and Biochemistry. 60:98-108.

Bouaziz, D., R. Jbir, S. Charfeddine, M.N. Saidi and R. Gargouri-Bouzid (2015). The StDREB1 transcription factor is involved in oxidative stress response and enhances tolerance to salt stress. Plant Cell Tissue Organ Culture. 121(1):237-248.
Byun, M., H.B.K. Won and S.C. Park (2007). Re-cent advances in genetic engineering of potato crops for drought and saline stress tolerance. Adadvances in Molecular Breeding towards Drought and Salt Tolerant Crops. pp. 713-737.

Charfeddine, M., S. Charfeddine, D. Bouaziz, R.B. Messaoud and R.G. Bouzid (2017). The effect of cadmium on transgenic potato (Solanum tuberosum) plants overexpressing the StDREB transcription factors. Plant Cell Tissue Organ Culture. 128(3):521-541.

Chen, M., Q.Y. Wang, X.G. Cheng, Z.S. Xu, L.C. Li, X.Y. Ye, L.Q. Xia and Y.Z. Ma (2007). GmDREB2, a soybean DRE-binding transcription factor, conferred drought and highsalt tolerance in transgenic plants. Biochemical and Biophysical Research Communications. 353(2):299-305.

Chinnusamy, V., M. Ohta, S. Kanrar, B.H. Lee, X. Hong, M. Agarwal and J.K. Zhu (2003). CE1: a regulator of cold-induced transcriptome and freezing tolerance in Arabidopsis. Genes \& Development. 17(8):1043-1054.

Coleman, M.L., E.A. Sahai, M. Yeo, M. Bosch, A. Dewar and M.F. Olson (2001). Membrane blebbing during apoptosis results from caspasemediated activation of ROCK I. Nature Cell Biology. 3(4):339-345.

Çulha Ş. and H. Çakırlar (2011). The effect of salinity on plants and salt tolerance mechanisms. Afyon Kocatepe Üniversitesi Fen Bilimleri Dergisi. 11:11-34.

Dubouzet, J.G., Y. Sakuma, Y. Ito, M. Kasuga, E.G. Dubouzet, S. Miura, M. Seki, K. Shinozaki and K. Yamaguchi-Shinozaki (2003). OsDREB genes in rice, Oryza sativa L., encode transcription activators that function in drought-, high-salt- and cold-responsive gene expression. The Plant Jl. 33(4):751-763.

Düzgüneş, O., T. Kesici and F. Gürbüz (1983). İstatistik Metotları 1. Ankara Üniversitesi Ziraat Fakültesi. Yayınları No: 862, Ankara.

El-esawi, M.A and A.A. Alayafi (2019). Overexpression of StDREB2 transcription factor enhances drought stress tolerance in cotton (Gossypium barbadense L.). Gene. 14;10(2):2-15.

Evers, D., S. Bonneche're, L. Hoffmann and J.F. Hausman (2007). Physiological aspects of abiotic stress of abiotic response in potato. Belgian J. Botany. 140(2):236-245.

Gutha, L.R and A.R. Reddy (2008). Rice DREB1B promoter shows distinct stress-specific responses, and the overexpression of cDNA in tobacco confers improved abiotic and biotic stress tolerance. Plant Molecular Biology. 68(6): 533-555. 
Hong, J.P. and W.T. Kim (2005). Isolation and functional characterization of the Ca-DREBLP1 gene encoding a dehydration-responsive element binding-factorlike protein 1 in hot pepper (Capsicum annuum L. cv Pukang). Planta. 220(6):875-888.

Hussain, S.S., M.A. Kayani and M. Amjad (2011). Transcription factors as tools to engineer enhanced drought tolerance in plants. Biotechnology Progress. 27(2):297-306.

Katerji, N., J.W. Van Hoorn, A. Hamdy and M. Mastrorilli (2003). Salt tolerance classification of crops according to soil salinity and to water stress day index. Agricultural Water Management. 43(1):99-109.

Koçak, N., H.A.A. Ahmed, G. Akdoğan, S. Arslan, D. Köm, E.M. Kara and S. Uranbey (2016). Effects of salinity on microtuberization of different potato genotypes. The $7^{\text {th }}$ International Scientific Agriculture Symposium Jahorina mountain (Bosnia and Herzegovina), 6-9 October.

Kreps, J.A., Y. Wu, H.S. Chang, T. Zhu, X. Wang and J.F. Harper (2002). Transcriptome changes for Arabidopsis in response to salt, osmotic, and cold stress. Plant Physiology. 130(4):21292141.

Lata, C. and M. Prasad (2011). Role of DREBs in regulation of abiotic stress responses in plants. J.Experimental Botany. 62(14):4731-4748.

Liu, L., M.J. White and T.H. MacRae (1999). Transcription factors and their genes in higher plants functional domains, evolution and regulation. European J. Biochemistry. 262(2):247-257.

Mizoi, J., K. Shinozaki and K. Yamaguchi-Shinozaki (2012). AP2/ERF family transcription factors in plant abiotic stress responses. Biochimica Biophysica Acta. 1819(2):86-96.

Murashige, T. and E.A. Skoog (1962). A revised medium for rapid growth and bioassay with tobacco tissue cultures. Physiologia Plantarum. 15:473497.

Reis, R.R., B.A. Da Cunha, P.K. Martins, M.T. Martins, J.C. Alekcevetch, A. Chalfun Jr, A.C. Andrade, A.P. Ribeiro, F. Qin, J. Mizoi, K. YamaguchiShinozaki, K. Nakashima, F. Carvalho Jde, C.A. De Sousa, A.L. Nepomuceno, A.K. Kobayashi and H.B. Molinari (2014). Induced overexpression of AtDREB2A CA improves drought tolerance in sugarcane. Plant Science. 221222:59-68.

Rensink, W.A., S. Iobst, A. Hart, S. Stegalkina, J. Liu and C.R. Buell (2005). Gene expression profiling of potato responses to cold, heat, and salt stress. Functional \& Integrative Genomics. 5: 201-207.
Saif-ur-Rasheed, M., S. Asad and Y. Zafar (1998). Use of radiation and in vitro techniques for development of salt tolerant mutants in sugarcane and potato. International Atomic Energy Agency. 32(32):61-74.

Shimazaki, T., T. Endo, M. Kasuga, K. YamaguchiShinozaki, N.K. Watanabe and A. Kikuchi (2016). Evaluation of the yield of abiotic-stress tolerant AtDREB1A transgenic potato under saline conditions in advance of field trials. Breeding Science. 66(5):703-710.

Stockinger, E.J., S.J. Gilmour and M.F. Thomashow (1997). Arabidopsis thaliana CBF1 encodes an AP2 domain-containing transcriptional activator that binds to the C-repeat/DRE, a cis-acting DNA regulatory element that stimulates transcription in response to low temperature and water deficit. Proceedings of the National Academy of Sciences United States of America. 4;94 (3):1035-40.

Su, Y., M. Viquez-Zamora, D.D. Uil, J. Sinnige, H. Kruyt, J. Vossen, P. Lindhout and S.V. Heusden (2019). Introgression of genes for resistance against phytophthora infestans in diploid potato. American J. Potato Research. https://doi.org/10.1007/s12230-019-09741-8.

Thomashow, M.F. (2001). So what's new in the field of plant cold acclimation? Lots! Plant Physiology. 125:89-93.

Tuteja, N. (2007). Mechanisms of high salinitytolerance in plants. Methods in Enzymology 428:419-438.

Uranbey, S., C. Sevimay, M. Kaya, A. Ipek, C. Sancak, D. Başalma, C. Er and S. Özcan (2005). Influence of different co-cultivation temperatures, periods and media on Agrobacterium tumefaciens-mediated gene transfer. Biologia Plantarum. 49(1):53-57.

Uranbey, S., D. Köm, G. Akdoğan, H.A.A. Ahmed, N. Koçak and M.E. Kara (2017). The effects of salt stress on expression of Asg1 gene related stomatal resistance in potato. Mediterranean Agricultural Sciences. 30(3):235-238.

Van Verk, M.C., C. Gatz and H.J.M. Linthorst (2009). Transcriptional regulation of plant defense responses. Advances in Botanical Research. 51:397-438.

Viswanathan, C. and J.k. Zhu (2002). Molecular genetic analysis of cold-regulated gene transcription. Philosophical Transactions of the Royal Society of London. Series B, Biological Sciences. 357(1423):877-886.

Wang, X., X. Chen, Y. Liu, H. Gao, Z. Wang and G. Sun (2011). CkDREB gene in Caragana korshinskii is involved in the regulation of stress response to multiple abiotic stresses as an AP2/EREBP 
transcription factor. Molecular Biology Reports. 38(4):2801-2811.

$\mathrm{Xu}$, Z.S., M. Chen, L.C. Li and Y.Z. Ma (2011). Functions and application of the AP2/ERF transcription factor family in crop improvement. J. Integrative Plant Biology. 53(7):570-585.

Yamaguchi-Shinozaki, K and K. Shinozaki (1994). A novel cis-acting element in an Arabidopsis gene is involved in responsiveness to drought, low temperature, or high-salt stress. Plant Cell. 6(2):251-264.
Yamaguchi-Shinozaki, K. and K. Shinozaki (2006). Transcriptional regulatory networks in cellular responses and tolerance to dehydration and cold stresses. Annual Review of Plant Biology. 57:781-803.

Zhang, Z., H. Li, W. Zhou, Y. Takeuchi and K. Yoneyama (2016). Effect of 5-aminolevulinic acid on development and salt tolerance of potato (Solanum tubrrosum L.) microtubers in vitro. Plant Growth Regulation 49(1):27-34.

Zhu, J.K. (2007). Plant Salt Stress. Encyclopedia of life sciences. John Wiley \& sons, ltd. www.els.ne. 